\title{
Teaching tactics in tennis. A constraint-based approach proposal
}

\author{
Antonio Fonseca-Morales ${ }^{a} \&$ Rafael Martínez-Gallego ${ }^{b}$ \\ ${ }^{a}$ Campus Tenis Elianers, ${ }^{b}$ University of Valencia, Spain.
}

\begin{abstract}
The aim of this article is to provide a structure framed in constraint-based approach, which will help coaches to classify tactical exercises, and in turn, serve as a reference for the creation of new exercises depending on the objectives and the game situation they wish to develop. By way of example, a proposal is made for exercises for the serve situation, with the intention that these can serve as inspiration for coaches to create their own.
\end{abstract}

Key words: methodology, dynamical systems, learning, exercises.

Received: 20 April 2021

Accepted: 30 May 2021

Corresponding author: Antonio Fonseca-Morales. Email: anton. fon@gmail.com

\section{INTRODUCTION}

A sport such as tennis is characterised by taking place in an environment of constant uncertainty, where players are forced to adapt continuously, reacting to the many different stimuli that occur in a multitude of dynamic and unpredictable situations (Sanz et al., 2012). During matches and training sessions, there are many aspects that make every action different:

- Different strokes and movements

- The opponents

- Partners (doubles discipline)

- Types of surfaces

- Types of balls

- Climatic conditions

- Other...

Having framed tennis as an open skill sport, it is important to define the concept of tactics, as this will be closely related to the open nature of the sport. Tactics is associated with the players' decision making during the game based on the options available and the risks and opportunities associated with each option (Fuller and Alderson, 1990). Therefore, tactics will be related to the decisions players make regarding the use of their technical, physical and psychological resources to solve the changing situations that occur during the game.

Traditional tennis teaching methodologies are based on the principle of learning by reproducing ideal models, through constant repetitions of different patterns of play. However, if we understand that tennis is an open sport, with the characteristics mentioned above, coaches must create practice situations with conditions similar to those of matches (Sanz and Hernández., 2013). Therefore, it is very important to avoid training sessions and drills always focusing on repeating patterns under the

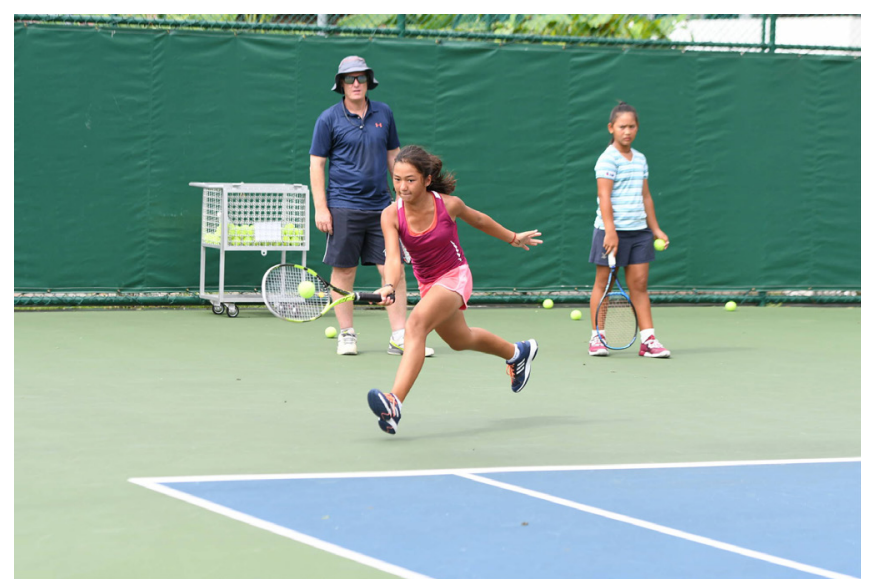

same conditions. The tactical training process should be based on learning produced in an environment that provides all possible stimuli to cope with the multiple game situations that tennis demands (Sahan et al., 2018). In doing so, players should develop their ability to adapt to the environment and make decisions that are best suited to each specific situation.

The proposal made in this article is based on an alternative model to cognitive learning proposals, mainly from the dynamic systems theory or the constraints led-approach. Constraints are pressures that limit or prevent certain movements, facilitating or allowing others (Davids et al., 2008). All categories of constraints from the environment (physical and social characteristics), the individual (personal characteristics) and the task (e.g. goals, rules and equipment) directly or indirectly influence decision-making and action in play. Therefore, a coach can manage player constraints, task constraints or environmental constraints to promote the emergence and development of successful performance. 


\section{Task constraints are based on:}

- Amplify the sources of information present in the context (e.g., place a rope over the net so that players focus their attention on the height of the ball).

- Gestures and a whole range of non-verbal actions that a coach can use (e.g., combined signals with players that can indicate which side to scan on the opponent, how high or how deep the ball should go, or whether to go further into or out of the court).

- Using verbal language, corresponding to the so-called augmented feedback and the interrogative method (e.g. two players play a point and the coach asks them if the pattern used during the point was the most appropriate one).

Individual constraints are based on:

- Structural constraints, which refer to morphology, body composition or skill level in a particular task, i.e. aspects of the individual that remain relatively constant over time.

- Functional constraints, which refer, among others, to thoughts or emotions (Araújo and Volossovitch, 2005).

Environmental constraints are based on:

- The effect of factors such as the presence and behaviour of the public or the presence of family members ("social constraints"), the conditions of the venue (e.g. temperature or brightness), or even the type of competition from an organisational point of view (e.g. regional tournament, national championship), on the performance of the players must also be considered. Although the manipulation of these factors is more difficult, it is important to consider their effect on performance and training.

- It is important to consider the influence of the coaching environment on players' performance and decisionmaking. The coach through his intervention can create two types of environments: player ego-oriented environment and player task-oriented environment (Roberts, et al., 2007).

Therefore, given the open-ended nature of tennis, and given the importance of creating training situations that provide the maximum possible stimuli to cope with the demands of the situations encountered during competition, constraint-based approach provides a theoretical framework and structure that can be very useful for the creation and classification of exercises for tactical training.

\section{PRACTICAL PROPOSAL}

In this section, based on the three categories of constraints and the five game situations, we propose a structure for classifying tactical training exercises and, as an example, we propose some exercises for training tactics in the serve situation.
Table 1 shows the proposed classification of tactical training exercises. It is proposed to classify the exercises into a total of 15 categories depending on the constraint being manipulated and the game situation.

Table 1

Structure for the classification of tactical training exercises

\begin{tabular}{llllll}
\hline & Serve & Return & Baseline & Net & Passing \\
\hline TASK & Cat. 1 & Cat. 4 & Cat. 7 & Cat. 10 & Cat. 13 \\
INDIVIDUAL & Cat. 2 & Cat. 5 & Cat. 8 & Cat. 11 & Cat. 14 \\
ENVIRONMENT & Cat. 3 & Cat. 6 & Cat. 9 & Cat. 12 & Cat. 15 \\
\hline
\end{tabular}

Proposed exercises

\section{Exercise Category 1 (Task constraint for serve situation)}

- Objective: Pattern selection.

- Description: The receiver shall change his position before the serve. Accordingly, the server should use a pattern in the serve that is appropriate to the position of the receiver.

- Premises and/or variations: The receiver shall change his position just as the server throws the ball.

\section{Category 2 exercise (Individual constraint for serve situation)}

- Objective: Consistency.

- Description: The server does a series of explosive drills for $15 \mathrm{sg}$ ( e.g. two 360 degree jump turns, several kangaroo jumps, quick skipping in place $5 \mathrm{sg}$ and a pushup) and then starts the point with a single serve.

- Premises and/or variants: vary the exercises and duration according to the level of play and the degree of fatigue of the player.

\section{Exercise Category 3 (Environmental constraint for serve situation)}

- Objective: Stabilisation of patterns.

- Description: The player will listen to different types of noises/sounds for $15 \mathrm{sg}$ in the service position. He then has to perform the pattern of play previously indicated by the coach.

- Premises and/or variants: at the end of the point, the coach will ask for information about the song (author, title, etc...).

\section{CONCLUSIONS}

The aim of this article is to provide a framework with which to plan and develop tennis drills and tasks through a classification based on constraint-based approach and game situations.

As previously indicated, the classification is based on dynamic learning theories, which argue that the constraints of a training task should be representative of the context for which this experience is intended to provide. Thus, we must ensure that 
the requirements of the proposed tasks correspond to the characteristics and requirements of the performance context for which the results are intended to be applied. Therefore, it is essential that the coach's intervention seeks to ensure training exercises that allow the perception-action coupling to be established based on the information that is available in the game context. (Carvalho et al., 2011).

\section{REFERENCES}

Araújo, D. and Volossovitch, A. (2005). Fundamentos para o treino da tomada de decisão: uma aplicação ao Andebol. In D. Araújo (Ed.), O Contexto da decisão: a acção táctica no desporto (pp. 75-97). Lisbon: Edições Visão e Contextos.

Carvalho, J. et al. (2011). Decision-making training in tennis: what scientific foundations can be applied in training programmes? Journal of Sport Psychology 2011. Vol. 20, no. 2, pp. 767-783.
Davids, K., Button, C. and Bennett, S. (2008). Dynamics of skill acquisition: A constraints-led approach. Champaign, IL: Human Kinetics.

Fuller, N., \& Alderson, G. J. K. (1990). The development of match analysis in game sports. Match Analysis in Sport: A state of the art review.

Roberts, G., Treasure, D. and Conroy, D. (2007). Understanding the dynamics of motivation in sport and physical activity: an achievement goal interpretation. In G. Tenenbaum and R. Eklund (Eds.), Handbook of Sport Psychology (3rd ed., pp. 3-30). Hoboken, NJ: John Wiley.

Sahan A., Erman, K. A.,\& Ertekin E.(2018). The effect of a variable practice on tennis groundstroke learning of adult beginners. ITF Coaching and Sport Science Review, 74(26), 14-16.

Sanz, D. \& Hernández, J. (2013). Application of variable practice to technique training in tennis. ITF Coaching and Sport Science Review, 60(21), 21-23.

Sanz, D. Fernández, J., Zierof, P. \& Méndez, A. (2012). Variability during training sessions to develop coordination skills in the development of tennis players. ITF Coaching and Sport Science Review, 58, 16-18.

Copyright (C) 2021 Antonio Fonseca-Morales \& Rafael Martínez-Gallego

\section{(c) (i)}

This text is under a Creative Commons BY 4.0 license

You are free to Share - copy and redistribute the material in any medium or format - and Adapt the content - remix, transform, and build upon the material for any purpose, even commercially under the following terms:

Attribution: You must give appropriate credit, provide a link to the license, and indicate if changes were made. You may do so in any reasonable manner, but not in any way that suggests the licensor endorses you or your use. 